\title{
Project ASTRO: A Successful Model for Astronomer/Teacher Partnerships
}

\author{
By M. Bennett, A. Fraknoi \& J. Richter \\ Astronomical Society of the Pacific, 390 Ashton Avenue, San Francisco, CA 94112
}

\section{Overview}

Project ASTRO is designed to improve astronomy education and science literacy in grades 4-9 by creating effective working partnerships between teachers/youth leaders and astronomers (both professional and amateur). Key elements of the program include:

- training the teachers/youth leaders and astronomers together in inquiry-based "handson, minds-on"learning activities

- encouraging an active working partnership between the astronomer and the teacher/youth leader

- encouraging multiple visits by the astronomer to the classroom or youth group meetings.

The ASP conducted a Project ASTRO pilot in California from 1992-1995, funded primarily by the National Science Foundation. The success of the pilot led to a second grant from NSF (1996-1998) to expand Project ASTRO to several other cities in the United States.

In the 3-year pilot project a total of 104 astronomers and 150 teachers formed 96 teams. More than $85 \%$ of the astronomers visited their adopted classrooms four or more times, with $46 \%$ making 5-10 visits during the school year. Approximately 10,000 students were involved. The Project ASTRO staff developed an extensive set of astronomy activities and tested resources, now available from the ASP as The Universe at Your Fingertips: An Astronomy Activity and Resource Notebook. The staff also published the Project ASTRO How-To Manual for Teachers and Astronomers.

In the first years, astronomers and teachers received stipends for attending training workshops. All participants either volunteered their time or were given release time by their employers for all time involved in planning and implementing their partnership visits and activities.

The independent evaluator rated the project "extremely successful", noting that $91 \%$ of the teachers felt they were teaching more astronomy as a result of the project. Most of the astronomers felt that they had learned a great deal about how children learn and how to develop problem solving and reasoning ability in children. As another indicator of the project's success, $62 \%$ of the teams continued the partnership on their own after their initial year.

In the expansion phase, Project ASTRO programs will be formed in 6-10 communities in the US. Science centers, planetaria, universities, school districts, or other astronomy and education institutions will take the lead in replicating the project locally. The goal of the project is to learn the most effective methods for forming and maintaining Project ASTRO programs that are locally self-sustaining.

\section{Background - The Astronomical Society of the Pacific}

The ASP is a worldwide scientific and educational organization founded in 1889 that brings together professional astronomers, educators, amateur astronomers, and interested laypeople. Technical publications include the well-known ASP Conference Series 
and Publications of the ASP. The ASP also publishes a popular bi-monthly magazine, Mercury.

Educational activities include an annual two-day summer workshop in astronomy, generally attended by 100-200 teachers, held since 1980 , and the quarterly Universe in the Classroom, a free education newsletter currently reaching over 12,000 teachers worldwide. The newsletter is currently translated into 14 languages.

As part of the ASP's annual meeting, held in various North American cities, the society for the past several years has also been cosponsoring with Astronomy magazine a public weekend event of lectures, demonstrations, and commercial exhibits, which often attracts over 2,000 people.

\section{The ASTRO Pilot Project1993-1995}

The pilot project consisted of the following major components:

- Recruitment and application process

- Selection and matching process

- Initial training

- Development of resource materials

- Implementation

- Evaluation of results

\section{Recruitment and Application Process}

Two application forms were developed-one for teachers and one for astronomers. These were distributed through appropriate local channels and networks. Teachers were recruited through local school districts, local branches of professional associations like the California Science Teachers Association, science education reform projects, and the state systemic initiative. All teacher applicants were required to demonstrate their school's commitment to the project by obtaining a signed release form from the principal of their school.

Astronomers were recruited through the ASP's mailing list, university astronomy departments, and amateur astronomical societies. Astronomers were required to indicate their time availability and commitment to the project.

Response to the program by both teachers and astronomers was high; nearly 10 teachers applied for each available slot.

\section{Selection and Matching Process}

Application forms were reviewed by project staff using criteria such as geographic area, balanced representation of grade levels, willingness to use activity- oriented teaching methods, ethnic and gender representation, and representation of urban, suburban, and rural districts.

Approximately $70 \%$ of the teachers were from elementary schools, $24 \%$ were from middle schools, and $5 \%$ were from high schools. Sixty-five percent of the teachers indicated they had minimal previous astronomy training or had not taught astronomy prior to their involvement with Project ASTRO.

Twenty-four percent of the astronomers were professional astronomers, $13 \%$ were professional astronomy educators (in planetaria or community colleges), and $63 \%$ were amateur astronomers. Few of the astronomers had any experience teaching any subject at the elementary grade levels. 
Project ASTRO staff selected teams based on geographical proximity, common interests, prior experience teaching astronomy to particular age groups, and ethnic and gender considerations. In $62 \%$ of the teams one astronomer was paired with one teacher ; the remaining third consisted of one astronomer paired with two teachers.

\section{Initial Training}

All participants were required to attend a two-and one-half-day training workshop, usually held during the summer, where, in most cases, teammates met their partners for the first time. The primary objective of the workshops was to train both astronomers and teachers in activity-based, age-appropriate classroom methods that engage students in problem solving and critical thinking. The workshop also provided the teams with help and guidance in beginning their individual planning processes.

Astronomers' and teachers' responsibilities and expectations were discussed and defined. Some astronomers, particularly some of the amateurs with less knowledge of astronomy, were relieved to discover that they were not expected to always know the answer to every question or to know all the constellations. Teachers were encouraged to be active members of the teaching team while continuing to be responsible for class organization and student behavior.

\section{Development of Resource Materials}

During the pilot project, the staff, assisted by the project participants and consulting master teachers, compiled, tested, revised, and finally published The Universe at Your Fingertips: An Astronomy Activity and Resource Notebook. More than 800 pages long, it contains more than 90 classroom and group activities, drawn from many existing curriculum projects and other publications. In addition, content notes, articles about teaching and learning, bibliographies, and resource lists were included. The publication has been favorably reviewed in several astronomy and educational periodicals.

The Project ASTRO How-To Manual for Teachers and Astronomers, a 32-page booklet with many tips and suggestions for how to create and maintain partnerships, was published in 1996.

Both publications are available from the Astronomical Society of the Pacific.

\section{Implementation}

Although Project ASTRO had recommended that astronomers visit their classrooms a minimum of four times, including an initial observation visit, most astronomers visited more frequently. More than $46 \%$ visited between $5-10$ times and another $13 \%$ visited more than 10 times. Only $15 \%$ visited fewer than 4 times.

Astronomers and teachers engaged in a number of different activities during the visits. In many cases, the teacher took the lead in suggesting and developing partnership activities, and in helping astronomers gain confidence in working with young people. Conducting activities from the resource materials, particularly those which had been modeled at the workshop, was the most common activity. Organizing and conducting star parties, often held on the school grounds and involving families and other classes, was the second most common activity. Other activities included assembly (large group) presentations, slide show and video presentations, using school computers and network connections, working with student clubs, organizing field trips, daytime telescope viewing, refurbishing the school planetarium, and various planning activities. 
During the first two years of the project, groups of teams were formed in several California cities. Separate workshops were held in the San Francisco Bay Area (northern California) and in the Los Angeles area (southern California). In the third year, new teams were formed and workshops held only in northern California. Project staff elected not to formally continue the project in southern California because it was decided that the project works best if managed locally. A few partnerships, however, did continue on their own in southern California. A total of 104 astronomers and 150 teachers formed 96 teams. Approximately 10,000 students participated in Project ASTRO over the threeyear period.

To improve communications and long-term networking between teams, the Project ASTRO staff publishes a quarterly newsletter, the ASTROgram, which is mailed to all teachers and astronomers who have participated in the program. It contains case histories and "success stories" written by participants, announcements of upcoming events, etc. All participants with email addresses (more astronomers than teachers) are placed on the project's email "exploder", but so far use of email has been light.

A few times a year, participants from both current and past years are invited to attend follow-up workshops, often featuring a combination of astronomy content and additional training in hands-on activities.

\section{Results}

A major goal of Project ASTRO was to increase the amount of astronomy taught in classrooms, as well as to increase the use of inquiry-based activities. More than $90 \%$ of the Project ASTRO teachers report that they are teaching more astronomy as a result of the project. In many cases, Project ASTRO seemed to empower teachers to use more creative approaches to teaching, as well as to focus on more hands-on, constructivist activities.

There also was evidence that the program influenced teachers' attitudes towards teaching girls about science. The workshops included a session sensitizing participants to issues related to gender, and one female teacher, partnered with a male amateur astronomer, reported that the Project ASTRO experience had changed her whole perspective on teaching, particularly teaching girls. She felt that she was far more sensitive to the importance of encouraging girls in her classes.

Project ASTRO also had a significant impact on the participating astronomers, exciting them about astronomy teaching, training them to teach effectively, and providing a valid and respected entré into the school systems by improving their abilities to be effective science education advocates and teachers in their communities. There were no differences in the success rates of professional astronomers, amateur astronomers, or astronomy educators.

Although design of the project did not include direct measurement of student learning, there is considerable evidence that impact on the students was substantial. More than $80 \%$ of teachers and astronomers indicated they believe that students had become more interested in astronomy as a result of the project, and $74 \%$ said that the students had actively learned more astronomy. Impacts included exciting students about the topic, providing opportunities for them to be active learners, and using their discretionary time by involving them (and often their families) in field trips, after-school clubs, and star parties. One fifth-grade class won a city-wide Mind Olympiad that focused on astronomy, and the teacher attributed their victory to Project ASTRO.

In three California communities (Stockton, Santa Barbara, and Sacramento), small groups of astronomers and teachers have formed their own "mini" Project ASTRO groups, 
recruited and trained new participants, and continued with limited financial support from the main project.

It is clear that the success of Project ASTRO is the result of the combination of three key factors - the formation of true working partnerships between teachers and astronomers, the emphasis on multiple visits by the astronomers, and the increased use of activity-based teaching methods over lecture-based techniques.

\section{The Project ASTRO Expansion Program}

In 1996 the NSF funded a three-year expansion grant for Project ASTRO, consisting of three main elements:

- continuation of the San Francisco Bay Area program

- expansion to 6-10 other cities in the United States

- development of a training program for individual astronomers

The primary goal of the new project is to explore methods for replicating self- sustaining Project ASTRO efforts in other communities. One replication strategy being encouraged is for expansion sites to form local coalitions of cooperating institutions to support the program. Part of the three-year project is to explore effective strategies to make the expansion sites self-sustaining.

In the expansion phase, increased emphasis will be placed on including youth group leaders, rather than just classroom teachers, in partnerships. Continuing emphasis will also be placed on reaching young people typically underrepresented in the physical sciences, particularly girls, children of color, and children in lower socioeconomic status groups.

\section{The San Francisco Bay Area Program}

The Bay Area Project ASTRO Coalition (BAPAC) consists of nearly 20 representatives of local school districts, amateur astronomy groups, university astronomy and/or science education departments, science centers, planetaria, and museums. The purpose of the Coalition is to support the continuation of the local ASTRO group and to eventually find resources and funding to support the modest administrative costs of continuing the program.

In the spring of 199620 new astronomers and 23 teachers were recruited to form a new Project ASTRO group for the 1996-97 academic year. A two-day workshop, to be held at one of the local county education offices, is scheduled for August, with the teams expected to begin working together in the fall 1996 semester.

\section{National Expansion}

How can the Project ASTRO model be successfully transferred to other localities? What are the key elements needed to create and sustain a local Project ASTRO? These are the questions that will be explored in the next three years.

The Project ASTRO staff intends to identify and recruit "lead institutions" in a total of 6-10 US cities. These institutions will be responsible for recruiting, matching, and training ASTRO partners, for generating interest and support among other local institutions, and for finding sources of ongoing support. The lead institution will receive "seed" funding to support project coordination, training, and purchase of materials, but within three years it is hoped that the local Project ASTRO program will become self-supporting. 
The Adler Planetarium in Chicago, Illinois is the lead institution of the first such expansion site. They are in the process of recruiting participants and will hold their first training workshop in August, 1996. Project ASTRO staff expects to identify at least two other institutions in other cities by the end of 1996 , so they can begin operations in the spring of 1997.

\section{The Astronomer Partners Program (APP)}

A "second strand" of the ASTRO Expansion grant is to find a way whereby individual astronomers (usually in non-ASTRO cities), with an interest in becoming more personally involved in science education, can use the Project ASTRO model to channel their efforts more effectively.

Approximately three one-day workshops per year are planned, to be held in conjunction with major national or regional professional and amateur astronomy meetings. Participants will be given an introduction to current issues in science education reform, and to the importance and effectiveness of activity-based age- appropriate learning techniques. They will also be given some tips on how to identify and recruit interested local teachers or youth group leaders with which to partner. Participants also receive a full set of resource materials. These astronomers, and the teachers and youth group leaders they work with, will become part of the national Project ASTRO network, receiving the ASTROgram, having access to email communications, etc.

The first APP workshop was held at the ASP annual meeting in June 1996, with 19 participants. The next is scheduled to be held in conjunction with the AAS meeting in Toronto in January 1997.

\section{Conclusion}

Many astronomers - researchers, educators and amateurs - wish to share their enthusiasm and energy with young people in schools and youth groups. Project ASTRO has demonstrated that this wonderful spirit of volunteerism, this desire to help and inspire children, can be channeled, leveraged, and made even more effective by combining three key elements forming ongoing partnerships with teachers and youth group leaders, learning how to conduct age-appropriate inquiry-based activities, and making multiple visits. The benefits of Project ASTRO extend far beyond the students themselves, giving the teachers and astronomers themselves new skills and understanding they will use throughout their careers. As astronomers become more personally involved with the realities of science education in U.S. schools, and more informed about the alternatives presented by the science reform movement, they will themselves become more effective agents for change, both in the schools they visit and beyond.

\section{Acknowledgments}

The Project ASTRO pilot and expansion programs have been funded by the NSF office of Informal Science Education, NASA Office of Space Science and Office of Education, the Banbury Fund, and the Bart Bok Fund of the ASP. The evaluation of the pilot project was conducted by Lynn Dierking of Science Learning, Inc. 


\section{REFERENCES}

Dierking, L. \& Richter, J., 1995, Project ASTRO: Astronomers and Teachers as Partners in Science Scope, Mar. 1995, p. 5.

Fraknol, A., ed., 1995, The Universe at Your Fingertips: An Activity and Resource Notebook for Teaching Astronomy. Project ASTRO, Astronomical Society of the Pacific.

Fraknol, A., Richter, J. \& Hidreth, S., Project ASTRO: Partnerships Between Astronomers and Teachers in J. Percy, ed., Astronomy Education: Current Developments, Future Coordination. 1996, Astronomical Society of the Pacific Conference Series.

Marino, K., Education Programs Let JPL Give Back to the Community: Project ASTRO Links Astronomers and Elementary Students Statewide in JPL Universe, Dec. 29, 1993, p. 1.

Richten, J. \& FraknoI, A., Matches Made in the Heavens: The A.S.P.'s Project ASTRO in Mercury, Sep./Oct. 1994, p. 24.

Richter, J. \& Fraknoi, A., 1996, Project ASTRO How-to-Manual for Teachers and Astronomers. Project ASTRO, Astronomical Society of the Pacific. 